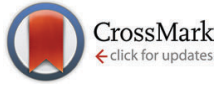

Cite this: J. Mater. Chem. B, 2015 3, 9053

Received 2nd September 2015, Accepted 23rd October 2015

DOI: 10.1039/c5tb01814e

www.rsc.org/MaterialsB

\title{
Zinc-imidazolate polymers (ZIPs) as a potential carrier to brain capillary endothelial cells $\dagger$
}

\author{
M. Chiacchia, ${ }^{\star a}$ C. Cerutti, ${ }^{b}$ R. Gromnicova, ${ }^{b}$ K. Rietdorf, ${ }^{b}$ I. A. Romero ${ }^{b}$ and \\ D. Bradshaw*a
}

\begin{abstract}
Herein, we report the synthesis and characterization of nanospheres of a biodegradable zinc-imidazolate polymers (ZIPs) as a proof-of-concept delivery vehicle into human brain endothelial cells, the main component of the blood-brain barrier (BBB). The ZIP particles can readily encapsulate functional molecules such as fluorophores and inorganic nanoparticles at the point of synthesis producing stable colloidal dispersions. Our results show that these biodegradable particles are not cytotoxic, and are able to penetrate and release cargo species to human brain capillary endothelial cells in vitro thus exhibiting significant potential as a novel platform for brain targeting treatments.
\end{abstract}

\section{Introduction}

Brain disorders have an enormous impact in societal and economic terms, and constitute a major public health problem in all high-income countries which is set to grow with increasingly ageing populations. ${ }^{1,2}$ Many neurodegenerative disorders including Alzheimer's, Multiple Sclerosis and Ischemia are largely aggravated from the weakening of the blood brain barrier (BBB), which is formed by the brain capillary endothelium composed of dense tight junctions between adjacent brain endothelial cells and is responsible for blocking harmful substances from entering the brain while allowing controlled access to necessary regulating compounds. ${ }^{3,4}$ Direct actions to prevent or correct BBB dysfunction in such diseases is challenging, but potential target treatments to the brain endothelium can be of primary importance to prevent the progression of many neurological diseases offering the possibility to reduce long-term illness. ${ }^{3,4}$

In recent years, the use of nanoparticles (NPs) as drug delivery vectors have become the subject of extensive investigations for the treatment of neurological disorders. ${ }^{5}$ NPs can play an essential role in delivery across the $\mathrm{BBB}$, and platforms based on liposomes, ${ }^{6}$ solid lipids, ${ }^{7}$ dendrimers, ${ }^{8}$ and polymeric particles ${ }^{9}$ bearing high loadings of therapeutic agents have all been utilised with varying degrees of success. The chemistry, structure and physical properties including size and surface charge of the NPs determine their potential for reaching the brain, and despite their diverse compositions and the

\footnotetext{
${ }^{a}$ School of Chemistry, University of Southampton, Highfield Campus, Southampton, UK. E-mail: M.Chiacchia@soton.ac.uk,D.Bradshaw@soton.ac.uk

${ }^{b}$ Department of Life, Health and Chemical Sciences, The Open University, Walton Hall, Milton Keynes, UK

$\dagger$ Electronic supplementary information (ESI) available: Including movies S1 and S2. See DOI: 10.1039/c5tb01814e
}

ready ability to modify NP surfaces, each delivery platform has its own limitations such as accumulation within the brain endothelium that may lead to possible long-term toxicity and adverse effects. ${ }^{10,11}$ Consequently, the formulation of new delivery platforms that allow enhanced uptake of therapeutics by the brain endothelium which minimise long term accumulation and do not compromise its barrier function are paramount to meet the increasing demands for the treatment of neurological diseases. ${ }^{10,11}$

Among the currently available nanodelivery systems, microporous metal organic frameworks (MOFs) have significant promise because of their high porosity, tailorable chemistry and in some cases biocompatibility. ${ }^{12-17}$ The vast majority of MOFs investigated for bio-delivery are crystalline in nature, and there remain fewer studies on the cellular uptake and drug delivery properties of their amorphous counterparts, which are often termed infinite coordination polymers (ICPs). ${ }^{18-20}$ ICPs exhibit several properties which separate them from conventional MOFs including a spherical shape, facile size control and occasionally metastable behaviour. ${ }^{18-21}$ They are typically prepared by triggered precipitation ${ }^{22}$ or in microemulsion-based systems ${ }^{23}$ where particle formation occurs within surfactant-stabilised emulsion droplets. They can be readily dispersed in a variety of media and their amorphous structures tend to disassemble more favourably in the presence of competitive ligands than their crystalline counterparts. Amorphous MOFs can also be obtained via post-synthetic reconstructive phase transitions starting from crystalline frameworks, although these methods typically result in particles of wide size distribution with random shapes often observed at the microscale level. ${ }^{24-30}$ With regard to nanodelivery applications, amorphous zirconium(Iv)-based MOFs have been shown to permit a sustained drug release when compared with crystalline MOFs of the same composition. ${ }^{31}$

To further fulfil the potential of amorphous MOFs as drug delivery systems for ameliorative therapies, it is desirable to 
conduct their syntheses in water to eliminate the presence of potentially harmful organic solvents while simultaneously yielding a uniform particle size. The choice of non-toxic metal ions and organic ligands is also important to reduce the footprint in biological systems, since these particles will break down to a degree in biological milieu. Herein, we report the direct synthesis of a zinc-imidazolate polymer (ZIP) under highly dilute aqueous conditions to yield uniformly sized nanospheres that can readily encapsulate fluorophores and inorganic NPs at the point of synthesis with extremely high loading efficiencies. We have evaluated whether the loaded ZIP particles could be used to potentially deliver therapeutic cargos to the human brain endothelium using the immortalized hCMEC/D3 human cerebral microvascular endothelial cell line, a wellestablished in vitro functional model for the human BBB, which expresses the same levels of transporters, cell-specific receptors and tight junction proteins found in healthy human brain microvessels (Fig. 1). ${ }^{32,33}$ Our results demonstrate the bare ZIP particles are stable in cell culture medium and are able to penetrate the hCMEC/D3 brain endothelial cells membrane to release their cargos within the cell cytoplasm.

\section{Experimental section}

\section{Synthesis of ZIP particles}

In a typical synthesis, $0.055 \mathrm{~g}$ of $\mathrm{Zn}\left(\mathrm{NO}_{3}\right)_{2} \cdot 6 \mathrm{H}_{2} \mathrm{O}(1.85 \mathrm{mM})$ is dissolved in $10 \mathrm{~mL}$ of deionized water and added to a solution consisting of $0.911 \mathrm{~g}$ of 2-MeIm (111 mM) and $0.911 \mathrm{~g}$ of 1-MeIm (111 mM) in $90 \mathrm{~mL}$ of deionized water. The final molar composition of the synthesis solution was $\mathrm{Zn}^{2+}: 2$-MeIm: 1-MeIm: water $=1: 60: 60: 30054$. The mixture was briefly mixed and allowed to react at room temperature without stirring. The mixture turned cloudy after $15 \mathrm{~min}$ and a suspension was obtained. After $24 \mathrm{~h}$, the suspension was centrifuged and washed three times with deionized water. The product was then freeze-dried for $24 \mathrm{~h}$. The yield is $30 \%$ based on the molar amount of zinc.

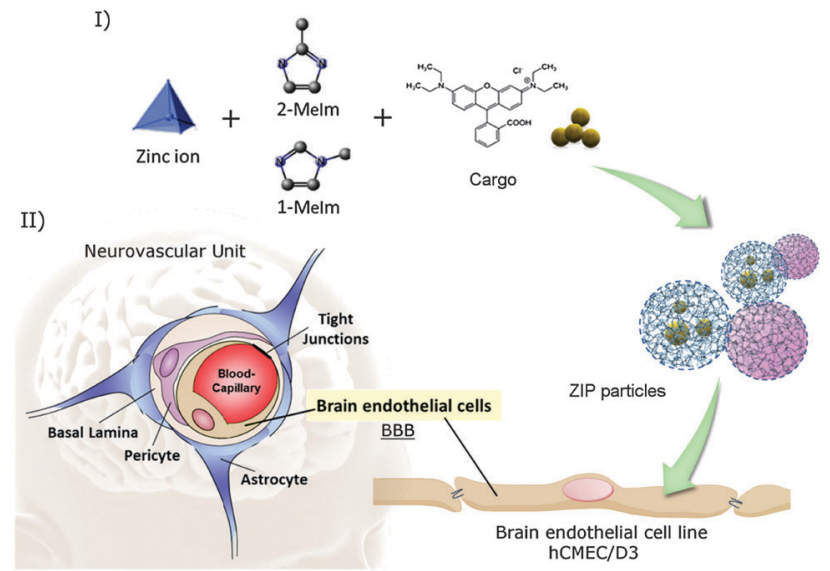

Fig. 1 Synthesis and assembly of loaded ZIP particles and their uptake into human brain endothelial cells. (I) Encapsulation process of cargo species into the ZIP matrices at the point of synthesis. (II) Cross-section of the human cerebral microvasculature and cell-uptake of loaded ZIP particles by the isolated and immortalized human brain endothelial cell line.

\section{Preparation of RhB@ZIP particles}

The synthesis of RhB@ZIP particles is based on the aforementioned synthesis of ZIP particles. For a typical synthesis, $0.2 \mathrm{~mL}$ of a $1 \mathrm{mg} \mathrm{mL}{ }^{-1}$ rhodamine $\mathrm{B}$ solution in water were added to the zinc solution and then mixed with a solution of 2-MeIm and 1-MeIm. After centrifugation the final solid showed an intense magenta colour and a clear supernatant was obtained.

\section{Preparation of AuNP@ZIP particles}

AuNP@ZIP particles were synthesized under same experimental conditions of the RhB-loaded ZIP material described above. The synthesis of PVP-stabilized Au NPs (13 nm in size) was based on a published procedure without any changes. ${ }^{34} 0.18 \mathrm{~mL}$ of Au NPs PVP-stabilized Au NPs (13 nm in size) were mixed with the zinc solution and then added to the imidazole solution. After workup, a pinkish solid was collected.

\section{Cargo release kinetics of loaded-ZIP particles}

RhB@ZIP and AuNP@ZIP particles were suspended in Hank's balanced salt solution (HBSS) $\mathrm{pH} 7.4$, sodium acetate buffer (NaOAc) pH 5.2 and Endothelial Cell Basal Medium-2 (EBM-2) culture medium (Lonza) pH 7.4 without phenol-red and with $2.5 \%$ Fetal Bovine Serum (FBS) solution + supplements at $37{ }^{\circ} \mathrm{C}$. At specific set points of time, the solid was separated and $2 \mathrm{~mL}$ aliquots of supernatant solution was withdrawn for fluorescence measurements. The fluorescence intensity of the supernatant solutions were measured using a Cary Eclipse fluorescence spectrophotometer (Agilent, Santa Clara, CA) at $\lambda_{\mathrm{ex}}=540 \mathrm{~nm}$ and $\lambda_{\mathrm{em}}=577 \mathrm{~nm}$. All measurements were performed in triplicate. The withdrawn solutions were replaced with $2 \mathrm{~mL}$ of fresh medium each time, in order to maintain sink conditions throughout the experiment.

\section{MTT Cytotoxicity assay of ZIP particles}

hCMEC/D3 cell monolayers were seeded in 96-well plates at a density of 30000 cells per well and cultured for 2 days in EBM-2 medium. The cell monolayers were washed three times in HBSS and incubated with medium containing ZIP particles at different concentrations $\left(0,2,4,6,8,16,25 \mu \mathrm{g} \mathrm{mL}^{-1}\right)$ and times $(0,1,3,6$, 12, $24 \mathrm{~h}$ ). Then, medium with $0.5 \mathrm{mg} \mathrm{mL}^{-1}$ of MTT reagent (3-[4,5-dimethylthiazol-2-yl]-2,5-diphenyl tetrazolium bromide) was transferred to each well. After $4 \mathrm{~h}$ of incubation, the medium was removed, and the cells were mixed with $0.1 \mathrm{~mL}$ of dimethylsulfoxide (DMSO) and the plate carefully shaken for $10 \mathrm{~min}$ prior to reading the absorbance at $540 \mathrm{~nm}$ using a FLUOstar Optima plate reader (BMG LABTECH, Tampa, USA). All treatments were performed in triplicate. Cell toxic agent digitonin $\left(30 \mu \mathrm{g} \mathrm{mL} \mathrm{m}^{-1}\right.$ for $30 \mathrm{~min}$ ) was used as a positive control, untreated cells without ZIP particles as a negative control and wells with cell medium only as a blank (Fig. S16, ESI $\dagger$ ).

\section{Cell culture and intracellular uptake studies}

The immortalized human brain endothelial cell line hCMEC/ D3 was cultured in Endothelial Cell Basal Medium-2 (EBM-2) culture medium (Lonza) as previously described. ${ }^{35}$ hCMEC/D3 
cells were grown on either collagen-coated 96-well plates or on permeable polyester 12 -well transwell inserts $(0.4 \mu \mathrm{m}$ pore, $12 \mathrm{~mm}$ diameter; Corning Costar, Buckingham, UK) coated with Collagen Type I from calf skin and treated with loaded-ZIP particles at the times and concentrations indicated for each experiment. Cultures were maintained in an incubator at $37{ }^{\circ} \mathrm{C}$ under an atmosphere of $5 \% \mathrm{CO}_{2}$ and $90 \%$ relative humidity. hCMEC/D3 cells were used in passages 25-30. Measurement of RhB@ZIP particles taken up by hCMEC/D3 cells was performed in a 96-well plate format. hCMEC/D3 cell were seeded in 96-well plates at density of 30000 cells per well and cultured for 2 days in EBM-2 medium. The cell monolayers were washed three times in HBSS and incubated with medium containing RhB@ZIP particles at different concentrations $\left(0,2,4,6,8,16,25 \mu \mathrm{g} \mathrm{mL}^{-1}\right)$ and times $(0,1,3,6,12,24 \mathrm{~h})$. After three washes with HBSS, the fluorescence intensity of $\mathrm{RhB}$ within the cells was measured using a FLUOstar Optima fluorescence plate reader (BMG LABTECH, Tampa, USA) $\lambda_{\mathrm{ex}}=540 \mathrm{~nm}$ and $\lambda_{\mathrm{em}}=577 \mathrm{~nm}$ (Fig. S18 and S19, ESI $\dagger$ ). Wells with hCMEC/D3 cells only were used to determine the autofluorescence of cells and subtracted from the measured fluorescence intensity. The software Optima version 2.00R3 (BMG LABTECH, Tampa, USA) was used to acquire and analyse the data. For AuNP@ZIP uptake studies, hCMEC/D3 cells (70000 cells per well) were seeded on collagen-coated 12-well transwell inserts (Corning Costar). The cell monolayers were washed three times in HBSS and a well dispersed solution of AuNP@ZIP particles were added in fresh culture medium $(0.5 \mathrm{~mL})$ in the upper chamber for $3 \mathrm{~h}, 12 \mathrm{~h}$ and $24 \mathrm{~h}$ at $4 \mu \mathrm{g} \mathrm{mL} \mathrm{m}^{-1}$ and $6 \mu \mathrm{g} \mathrm{mL} \mathrm{m}^{-1}$ at $37{ }^{\circ} \mathrm{C}$. After three washes with HBSS cells were fixed in $2.5 \%$ glutaraldehyde prepared in $0.1 \mathrm{M}$ Sörensons phosphate buffer (PB) for $1 \mathrm{~h}$ at room temperature. The cultures were then washed three times in phosphate buffer saline (PBS) and stored in PBS at $4{ }^{\circ} \mathrm{C}$ before further processing for electron microscopy.

\section{In vitro imaging study}

In vitro imaging was performed on live hCMEC/D3 cell monolayers seeded in a Ibidi ${ }^{\circledR} \mu$-Slides VI system consisting of 6 parallel channels (Ibidi GmbH) and incubated with RhB@ZIP particles for 3, 12 and $24 \mathrm{~h}$ at concentrations of $4 \mu \mathrm{g} \mathrm{mL} \mathrm{m}^{-1}$ and $6 \mu \mathrm{g} \mathrm{mL} \mathrm{m}^{-1}$. At the indicated times, cell nuclei were stained with Hoechst 33342 $\left(1 \mathrm{mg} \mathrm{mL}{ }^{-1}\right)$ for $10 \mathrm{~min}$ at $37^{\circ} \mathrm{C}$. The cells were then washed three times in HBSS and observed using a fluorescent microscope at magnification of $63 \times$ and $100 \times$ (Leica System-Leica AF6000 Series) (Fig. S21, ESI $\dagger$ ). Supporting movies of live hCMEC/D3 cell monolayers incubated with $6 \mu \mathrm{g} \mathrm{mL} \mathrm{m}^{-1}$ of RhB@ZIP particles for $1 \mathrm{~h}$ were also recorded with a speed of 0.5 frames per second (fps).

\section{Results and discussion}

In a typical experiment, ZIPs were synthesized by mixing aqueous solutions of zinc nitrate, 2-methylimidazole (2-MeIm) and 1-methylimidazole (1-MeIm) under conditions of very high dilution at room temperature forming a stable colloidal dispersion (Fig. S1, ESI $\dagger$ ). Scanning electron microscopy (SEM) and transmission electron microscopy (TEM) images of the white product recovered by centrifugation after $24 \mathrm{~h}$ reaction time at room temperature reveal monodisperse spherical particles of diameter $143 \pm 33 \mathrm{~nm}$ (Fig. 2a-d and Fig. S2, S3, ESI $\dagger$ ), and a comparable size distribution to other ICPs. ${ }^{18-20}$ The polydispersity index (PDI) for the particles was 0.07, indicating a good degree of homogeneity of the nanospheres.

The powder X-ray diffraction (PXRD) pattern of the ZIP particles (Fig. S4, ESI $\dagger$ ) shows no Bragg diffraction in the angular range examined, with a single broad peak caused by diffuse scattering which is consistent with an amorphous material. This was further confirmed by solid state ${ }^{13} \mathrm{C}$ NMR, where the three resonances at 14.4, 124.3 and $151.5 \mathrm{ppm}$, corresponding to the 2-MeIm framework-forming linker were significantly broader than a crystalline control of identical composition (Fig. S5, ESI $\dagger$ ). This is entirely consistent with an anisotropic and highly disordered structure as observed by PXRD, and further hints at the dynamic nature often associated with amorphous materials and in particular with ICPs.

Results obtained by ${ }^{1} \mathrm{H}$-NMR following particle digestion in hydrochloric acid, Infrared Spectroscopy (FT-IR) and Inductive coupled plasma optical emission spectrometry (ICP-OES) (Fig. S6, S7 and Table S1, ESI $\dagger$ ) show that ZIP particles have a composition of [ $\left.\mathrm{Zn}(2-\mathrm{MeIm})_{2}\right]$, identical to crystalline zeolitic imidazolate framework ZIF-8, which has previously been employed to deliver a number of exogenous chemical species into cancer cells. ${ }^{36-39}$ The absence of 1-MeIm in the ZIP particles as confirmed by ${ }^{1} \mathrm{H}-\mathrm{NMR}$ suggest that 1-MeIm can modulate the rate of reaction between the zinc centres and 2-MeIm through weak coordination interactions via a deprotonated amino group as reported for previous ZIF-8 preparations. ${ }^{40}$ The ZIP particles are thermally stable, decomposing in a single step at $380{ }^{\circ} \mathrm{C}$, and have a BET surface area of $46 \pm 5 \mathrm{~m}^{2} \mathrm{~g}^{-1}$ (Table S2, ESI $\dagger$ ). While the porosity is expectedly lower than crystalline ZIF-8 phases, it is entirely consistent with

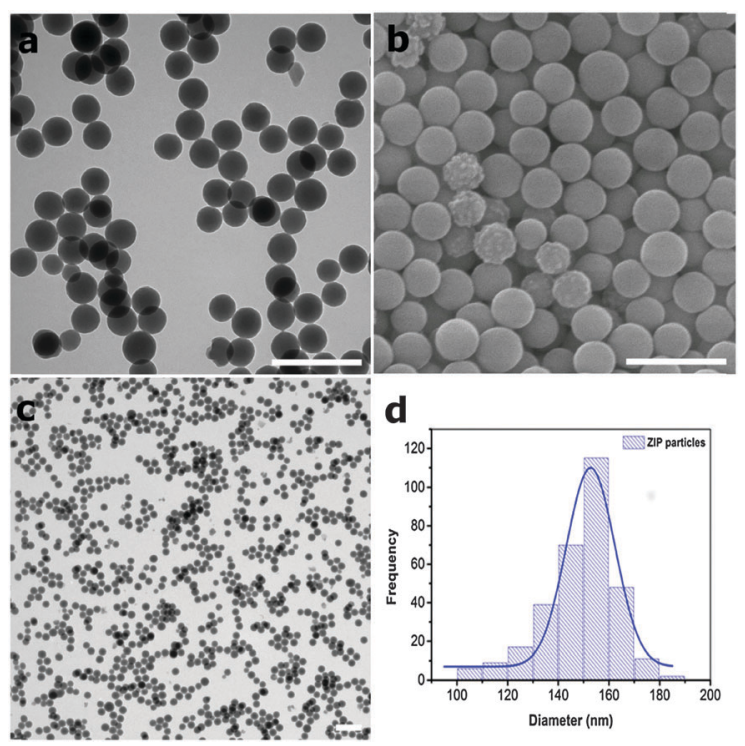

Fig. 2 (a-c) TEM and SEM images of as-synthesized ZIP particles. Scale bars $=500 \mathrm{~nm}$. (d) Particle size distribution of ZIP particles, $d=143 \pm 33$; $\mathrm{PDI}=0.07$. 
experimental measurements previously reported for postsynthetically amorphized ZIF-8 obtained via reconstructive phase transitions induced by ball milling, high temperature or high pressure. ${ }^{24,41}$ The $\zeta$-potential of bare ZIP particles dispersed in cell growth medium is $-28 \pm 2.5 \mathrm{mV}$ (Table S3, ESI $\dagger$ ), which is similar to other nanoscale ICPs and ZIFs measured in cell medium and employed in cell uptake and drug delivery studies, ${ }^{14}$ and pegylated silica NPs that have recently been reported to cross the BBB both in vitro and in vivo. ${ }^{10,42}$

The ZIP platform provides a facile means to load functional molecules and NPs at the point of synthesis as previously demonstrated for other ICP preparations, where these exogenous species become fully incarcerated within the amorphous matrix. ${ }^{19,21}$ This was demonstrated initially using two organic fluorophores, rhodamine $\mathrm{B}(\mathrm{RhB})$ and fluorescein isothiocyanate (FITC) as easily visualised model hydrophilic and hydrophobic drug compounds, respectively. For RhB, loading was effected by simply adding the fluorophore to the aqueous synthesis mixture yielding an intense magenta solid. Following removal of the magenta solid (RhB@ZIP), fluorescence measurements on the supernatant revealed a RhB loading efficiency in excess of $94 \%$ (Fig. 3a) of the available dye.

Thermogravimetric analysis (TGA) and ICP-OES indicate a total loading level of $2 \mathrm{wt} \%$ for RhB@ZIP (Fig. S8 and Table S1, ESI $\dagger$ ), which is progressively reduced when the fluorophore is added later in the synthesis $23.5 \%$ and $15 \%$ incorporation respectively, when $\mathrm{RhB}$ is added after $1 \mathrm{~h}$ and $5 \mathrm{~h}$ of ZIP synthesis; Fig. S9, ESI $\dagger$ ). This suggests that high loading levels of the fluorophore can be incorporated into the amorphous coordination matrix with minimal leaching, but only when present at the start of ZIP synthesis. The $\zeta$-potential of RhB@ZIP $(-23 \pm 2.3 \mathrm{mV}),{ }^{39}$ indicates that the fluorophore is largely

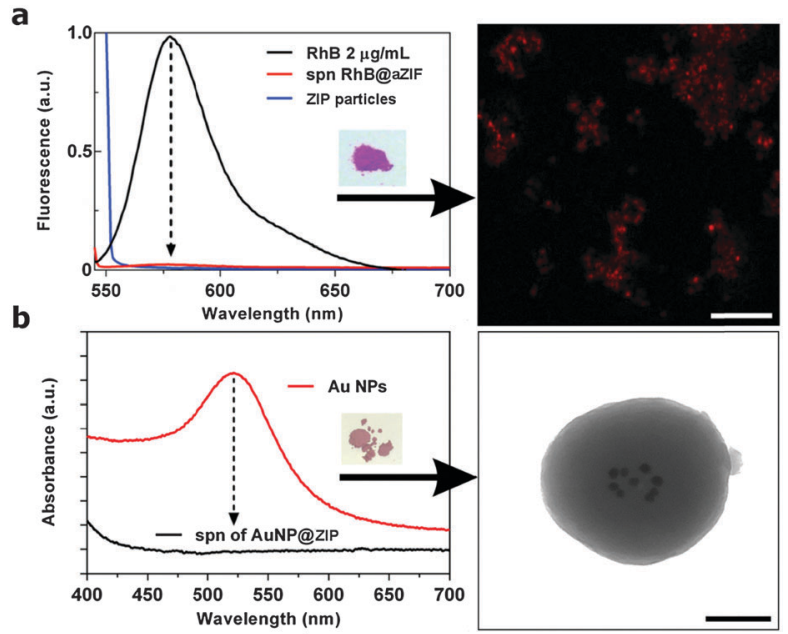

Fig. 3 (a) Fluorescence spectra showing the encapsulation of RhB in ZIP particles; inset shows the recovered magenta solid residue. Right side: fluorescent image of disperse RhBaZIP particles. Scale bar $=5 \mu \mathrm{m}$. (b) UV-Vis spectra of PVP-Au NPs encapsulated in ZIPs; inset shows the pink solid residue. Right side: TEM image of a single AuNP@ZIP nanosphere showing well dispersed and fully confined Au NPs within the ZIP matrix. Scale bar $=100 \mathrm{~nm}$. immobilized within the ZIP matrix rather than being adsorbed to its external surface, in good agreement with the leaching studies. TEM images of RhB@ZIP reveal a similar size and uniformity to the free ZIP nanospheres, indicating that the presence of RhB does not interfere with the assembly of the amorphous coordination-derived matrix (Fig. S10, ESI $\dagger$ ), and FT-IR and fluorescence microscopy further confirm the presence of RhB. The same procedure was applied to encapsulate FITC, but yielded ZIP particles of ill-defined morphology (Fig. S11, $\mathrm{ESI} \dagger)$. Under the $\mathrm{pH}$ conditions of the ZIP synthesis ( $\mathrm{pH} 9-10)$ the predicted theoretical surface charges for FITC and RhB are -1.80 and +0.23 , respectively. ${ }^{43}$ The negative charge on the FITC fluorophore suggests that it could ligate to $\mathrm{Zn}^{2+}$ during $\mathrm{ZIP}$ assembly, which could disrupt the particle formation. This is consistent with a recent report that crystalline ZIF-8 nanospheres with a positive $\zeta$-potential only encapsulate negatively-charged guests, ${ }^{39}$ and indicates that the physical properties of the guest are important to successful encapsulation and in the present case framework morphology.

Encapsulation was also demonstrated with polyvinylpyrrolidone (PVP) functionalized gold nanoparticles (Au NPs, $d=13 \mathrm{~nm}$, Fig. S12, ESI $\dagger$ ) which themselves have been demonstrated to be an effective therapeutic platform. ${ }^{44}$ The presence of PVP on the surface of the Au NPs increases their stability and enhances their affinity to the ZIP precursors. ${ }^{45}$ The ultraviolet-visible (UV-vis) absorption spectrum of the recovered supernatant showed no detectable localized surface plasmon resonance (LSPR) band for $\mathrm{Au}$, indicating all available Au NPs were incorporated into the ZIPs which was determined as $1.9 \mathrm{wt} \%$ by ICP-OES (Table S1, ESI $\dagger$ ). TEM images reveal isolated monodisperse ZIP particles each containing multiple non-aggregated Au NPs confined within the amorphous matrix (Fig. 3b and Fig. S13, ESI $\dagger$ ) and the PXRD pattern of the composite reveals a very weak and broadened peak at $2 \theta=38^{\circ}$ associated with the $\langle 111\rangle$ Au lattice plane (Fig. S14, ESI $\dagger$ ). Together, these results demonstrate that ZIP particles are an excellent platform for efficient encapsulation of small functional molecules and nanoscale objects and thus have potential as delivery vehicles in biological applications.

To assess their stability and release properties for potential applications in biodelivery, RhB@ZIP particles were soaked for $24 \mathrm{~h}$ in complete cell culture medium and buffer solutions at $37{ }^{\circ} \mathrm{C}$ at biologically relevant $\mathrm{pH}$ values (Fig. 4a and Table S4, $\mathrm{ESI} \dagger)$. We find $41 \% \mathrm{RhB}$ is released when the RhB@ZIP particles are soaked for $24 \mathrm{~h}$ at $37{ }^{\circ} \mathrm{C}$ in Endothelial Growth Basal Medium-2 (EBM-2) that includes $2.5 \%$ fetal bovine serum (FBS) and all supplements required for optimal cellular growth of hCMEC/D3 cells. ${ }^{32,33}$ A 24\% RhB release was observed from RhB@ZIP in Hank's balanced salt solution (HBSS) at pH 7.4 over a period of $24 \mathrm{~h}$. In the presence of sodium acetate buffer (NaOAc) at $\mathrm{pH} 5.2$ however, a progressive release occurred during the first 6 hours of incubation reaching $90 \%$ in $24 \mathrm{~h}$ as previously observed for drug release from some ICPs that are not surface coated to protect the networks from erosion. ${ }^{19,21,46,47}$ Similar release kinetics have also been observed for AuNP@ZIP particles in the presence of the cell culture medium and buffer solutions (Fig. S15 and Table S4, ESI†). 


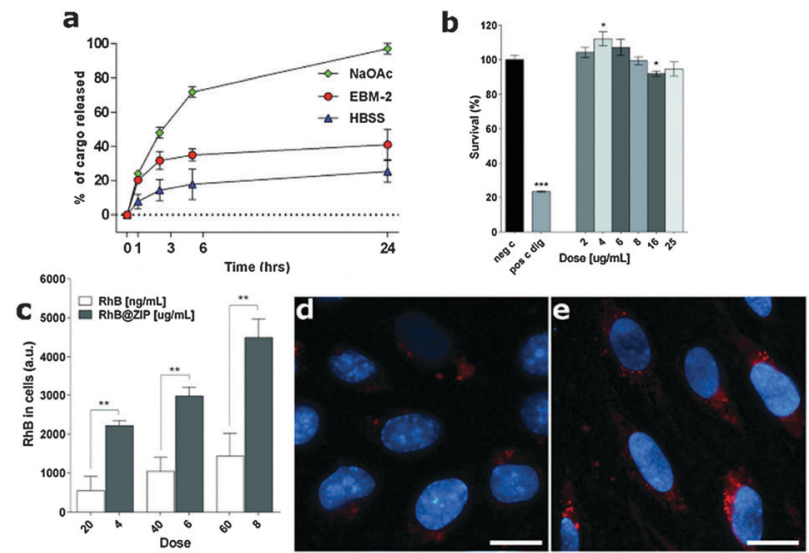

Fig. 4 (a) Kinetic release profiles of RhB from RhB@ZIP particles in different buffer solutions and cell culture medium at $37^{\circ} \mathrm{C}$. Sodium acetate ( $\left.\mathrm{NaOAC}\right)$ pH 5.2 buffer solution; complete Endothelial Cell Basal Medium-2 (EBM-2) culture medium pH 7.4 (without phenol-red); Hank's balanced salt solution (HBSS) pH 7.4 buffer solution. Data are displayed as mean $\pm \mathrm{SD},(n=3)$. (b) Viability of human brain endothelial cells incubated with increasing concentration of ZIP particles for $24 \mathrm{~h}$. Negative control were untreated cells (neg c) and digitonin-treated cells (dig, $30 \mu \mathrm{g} \mathrm{mL}^{-1}$ for $30 \mathrm{~min}$ ) were a positive control for cell death, $(n=2)$. (c) RhB released in cells by RhB@ZIP particles after $3 \mathrm{~h}$ incubation (background cell alone subtracted) vs. the amount of free RhB corresponding to the expected quantity released from the particles into the EBM-2 complete culture medium at $37{ }^{\circ} \mathrm{C}$ after the same incubation period, $(n=3)$. (d) Fluorescent images showing cellular uptake of free RhB (100 ng mL ${ }^{-1}$ ) and (e) RhB released in the cells by RhB@ZIP particles $\left(4 \mu \mathrm{g} \mathrm{mL}{ }^{-1}\right.$, total RhB contents $=80 \mathrm{ng} \mathrm{mL}^{-1}$ ) both following $3 \mathrm{~h}$ of incubation. In red, RhB fluorescence signal and in cyan, cell nuclei stained with Hoechst 33342. Scale bar $=20 \mu \mathrm{m}$. All data shown are mean \pm SEM and were analyzed by unpaired two-tail Student's $t$-test, ${ }^{*} P<$ 0.05 , ** $P<0.01$, ${ }^{* \star} P<0.001$, * significantly different from the controls.

An accelerated degradation of the ZIP carrier at low $\mathrm{pH}$ could possibly reduce the long-term risk of accumulation in the brain endothelium and potentially prevent adverse effects on its natural barrier function. The cargo-release behaviour of the bare ZIP particles compares well to the average release profiles of $20-50 \%$ over 12-24 h reported for most crystalline MOF-based cargo delivery systems when incubated in buffered media..$^{36-39,48-50}$ Moreover the ZIP particles show an improved and sustained release, most likely facilitated by their zinc-imidazolate composition, when compared to other (bare) ICPs in buffer solutions where an average release of up to $80 \%$ in the first $12 \mathrm{~h}$ is typical. ${ }^{18,19,21,46,47}$

Prior to cellular uptake studies the cytotoxicity of empty ZIP particles was evaluated against hCMEC/D3 brain endothelial cells in vitro, by MTT toxicity assay. hCMEC/D3 cells were exposed to a progressive concentration of ZIP particles (up to a maximum $25 \mu \mathrm{g} \mathrm{mL}{ }^{-1}$ ) for $24 \mathrm{~h}$. Minimal cytotoxicity of the ZIP particles was observed at all doses and incubation times tested (Fig. $4 \mathrm{~b}$ and Fig. S16, ESI $\dagger$ ). The pH of the EBM- 2 culture medium during cellular growth was also monitored for $24 \mathrm{~h}$ in order to anticipate a possible premature acid-induced release of the fluorophore from the loaded ZIPs outside the cells. We found that the $\mathrm{pH}$ of the culture medium remains in the optimum range (from $\mathrm{pH} 7.4$ to 7.0) over the time-course of the in vitro experiments (Fig. S17, ESI $\dagger$ ) indicating this is appropriate for the biodelivery experiments.
hCMEC/D3 endothelial cells were incubated in cell culture medium containing RhB@ZIP particles (up to $25 \mu \mathrm{g} \mathrm{mL} \mathrm{m}^{-1}$ ) over a period of $24 \mathrm{~h}$. After the required incubation period, cells were washed with HBSS in order to remove non-internalized particles. The amount of internalized $\mathrm{RhB}$ was evaluated by recording the fluorescence intensity within the whole cells. Increased fluorescence was readily observed after $1 \mathrm{~h}$ and $3 \mathrm{~h}$ of incubation when compared to free RhB controls (Fig. 4c and Fig. S18, ESI $\dagger$ ). Notably, we observed an increased fluorescence signal as both the incubation time and RhB@ZIP concentration increased (Fig. S19, ESI $\dagger$ ). The amount of free RhB used in the control experiments was equivalent to the concentration that would be expected to be released by the RhB@ZIP particles into the medium over the time-course experiments as determined from the release profiles shown in Fig. 4a. Thus for a concentration of $6 \mu \mathrm{g} \mathrm{mL} \mathrm{m}^{-1}$ of RhB@ZIP with a total RhB content of $120 \mathrm{ng} \mathrm{mL}^{-1}(2 \mathrm{wt} \%)$, the amount that would be released into the medium following $3 \mathrm{~h}$ of incubation is $c a .40 \mathrm{ng} \mathrm{mL}$.

Quantification of the cellular fluorescence intensity clearly shows an average 3 -fold increase of the RhB signal in the hCMEC/D3 cell cytoplasm upon delivering the fluorophore using RhB@ZIP particles compared to the free RhB controls. The intracellular dissolution of RhB@ZIP particles and subsequent release of RhB in hCMEC/D3 cells was further explored using live-cell fluorescent microscopy. Bright field images clearly show live cells with no morphological alterations of the typical spindle shape confirming the presence of a healthy cell monolayer during the in vitro studies (Fig. S20, ESI $\dagger$ ). The fluorescent images and data suggest an enhanced cellular uptake of the ZIP carrier compared to free RhB (Fig. 4d, e and Fig. S21, ESI $\dagger$ ) by the human brain endothelial cells across the concentration range tested. Upon live-cell imaging the RhB@ZIP particles were found to penetrate the endothelial cell membrane following $1 \mathrm{~h}$ and $3 \mathrm{~h}$ of incubation, with high intracellular trafficking observed in video-microscopy which suggest that ZIP particles may use the endosomal entry route (Movies S1 and S2, ESI $\dagger$ ). Images also showed high diffuse fluorescence within the cell cytoplasm which support the hypothesis of a pH-induced dissociation of the metal-ligand matrix along the endosomal pathway and subsequent release of RhB. ${ }^{39}$ We note that brain endothelial cells highly express P-glycoprotein (Pgp), an ATP-driven efflux pump which contributes to the BBB defence mechanism by pumping out foreign molecules. ${ }^{51-53}$ Thus the observed increase in fluorescence intensity may also include a contribution from enhanced cellular retention of the fluorophore in the presence of the carrier.

To evaluate the diversity of cargo that can be delivered to the brain endothelial cells, AuNP@ZIP particles were incubated with a brain endothelial cell monolayer for $3 \mathrm{~h}$ and $12 \mathrm{~h}$, and intracellular release investigated by TEM (Fig. S22, ESI $\uparrow$ ). Control samples with free Au NPs were performed following the same procedure. We found that the Au NPs released from AuNP@ZIP, while absent from cellular junctions, are localized throughout the endothelial cell cytoplasm including in vesicles, implying a vesicular transport process. We also observed that many Au NPs accumulated in the extracellular space between 
the basal plasma membrane and the polyester membrane filter of the transwell insert. The observed Au NP localisation within the cells is in agreement with previous reports of BBB models exposed to appropriately functionalised Au NPs. ${ }^{11,54,55}$ The AuNP@ZIP composite would thus appear to facilitate the internalization of the Au NPs into the cytosol, and once released are able to translocate inside the brain endothelial cells cytoplasm and exit through the basal membrane without using the paracellular route. The observed uptake of AuNP@ZIP particles and their intracellular release within hCMEC/D3 is in agreement with the observations for the RhB@ZIP.

\section{Conclusions}

We have reported the synthesis of biocompatible ZIP particles in water that are able to encapsulate diverse cargo species with great efficiency at the point of synthesis. The ZIP particles clearly display marginal cytotoxicity when compared to control samples, and are readily internalised by an in vitro BBB model whereupon their cargo is released most likely via $\mathrm{pH}$-induced dissociation of the matrix. While the released RhB promptly diffuses into the cell cytoplasm, ZIP particles also appear to facilitate the delivery of Au NPs across the in vitro BBB. These results indicate that bare ZIP particles have an appropriate size, hydrophobic/hydrophilic balance and surface charge allowing them to pass through the hCMEC/D3 human cerebral microvascular endothelial cell membrane via an endocytic entry route where their degradation and biologically benign composition could ensure minimum nanocarrier footprint in the cells. More studies are needed with respect to the exact cellular uptake mechanism, clearance rate and blood-stream stability of the ZIPs, but nevertheless this study provides a step forward in the formulation of potentially theranostic particles based on coordination-derived matrices for delivery to the brain endothelium and the treatment of related brain diseases and dysfunctions.

\section{Acknowledgements}

We gratefully acknowledge the European Research Council for funding under contract number ERC-2010-StG-258613-BIOMOF and Dr Marina Carravetta for collection of solid-state NMR data.

\section{Notes and references}

1 J. Olesen, A. Gustavsson, M. Svensson, H. U. Wittchen and B. Jönsson, Eur. J. Neurol., 2012, 19, 155-162.

2 M. DiLuca and J. Olesen, Neuron, 2014, 82, 1205-1208.

3 N. J. Abbott, A. A. K. Patabendige, D. E. M. Dolman, S. R. Yusof and D. J. Begley, Neurobiol. Dis., 2010, 37, 13-25.

4 G. A. Rosenberg, J. Cereb. Blood Flow Metab., 2012, 32, 1139-1151.

5 D. Mc Carthy, M. Malhotra, A. O'Mahony, J. Cryan and C. ODriscoll, Pharm. Res., 2014, 1-25, DOI: 10.1007/ s11095-014-1545-6.
6 P. J. Gaillard, C. C. M. Appeldoorn, R. Dorland, J. van Kregten, F. Manca, D. J. Vugts, B. Windhorst, G. A. M. S. van Dongen, H. E. de Vries, D. Maussang and O. van Tellingen, PLoS One, 2014, 9, e82331.

7 L. Gastaldi, L. Battaglia, E. Peira, D. Chirio, E. Muntoni, I. Solazzi, M. Gallarate and F. Dosio, Eur. J. Pharm. Biopharm., 2014, 87, 433-444.

8 L. Xu, H. Zhang and Y. Wu, ACS Chem. Neurosci., 2013, 5, 2-13.

9 D. Brambilla, J. Nicolas, B. Le Droumaguet, K. Andrieux, V. Marsaud, P.-O. Couraud and P. Couvreur, Chem. Commun., 2010, 46, 2602-2604.

10 M. N. Raghnaill, M. Bramini, D. Ye, P.-O. Couraud, I. A. Romero, B. Weksler, C. Aberg, A. Salvati, I. Lynch and K. A. Dawson, Analyst, 2014, 139, 923-930.

11 D. Ye, M. N. Raghnaill, M. Bramini, E. Mahon, C. Aberg, A. Salvati and K. A. Dawson, Nanoscale, 2013, 5, 11153-11165.

12 R. C. Huxford, J. Della Rocca and W. Lin, Curr. Opin. Chem. Biol., 2010, 14, 262-268.

13 S. Keskin and S. Kızlel, Ind. Eng. Chem. Res., 2011, 50, 1799-1812. 14 C. Tamames-Tabar, D. Cunha, E. Imbuluzqueta, F. Ragon, C. Serre, M. J. Blanco-Prieto and P. Horcajada, J. Mater. Chem. B, 2014, 2, 262-271.

15 À. Ruyra, A. Yazdi, J. Espín, A. Carné-Sánchez, N. Roher, J. Lorenzo, I. Imaz and D. Maspoch, Chem. - Eur. J., 2015, 21, 2508-2518.

16 C. He, K. Lu and W. Lin, J. Am. Chem. Soc., 2014, 136, 12253-12256.

17 P. Horcajada, R. Gref, T. Baati, P. K. Allan, G. Maurin, P. Couvreur, G. Férey, R. E. Morris and C. Serre, Chem. Rev., 2012, 112, 1232-1268.

18 C. M. Calabrese, T. J. Merkel, W. E. Briley, P. S. Randeria, S. P. Narayan, J. L. Rouge, D. A. Walker, A. W. Scott and C. A. Mirkin, Angew. Chem., Int. Ed., 2015, 54, 476-480.

19 I. Imaz, M. Rubio-Martinez, L. Garcia-Fernandez, F. Garcia, D. Ruiz-Molina, J. Hernando, V. Puntes and D. Maspoch, Chem. Commun., 2010, 46, 4737-4739.

20 D. Liu, C. Poon, K. Lu, C. He and W. Lin, Nat. Commun., 2014, 5, 4182.

21 I. Imaz, J. Hernando, D. Ruiz-Molina and D. Maspoch, Angew. Chem., Int. Ed., 2009, 48, 2325-2329.

22 M. Oh and C. A. Mirkin, Nature, 2005, 438, 651-654.

23 W. Lin, W. J. Rieter and K. M. L. Taylor, Angew. Chem., Int. Ed., 2009, 48, 650-658.

24 S. Cao, T. D. Bennett, D. A. Keen, A. L. Goodwin and A. K. Cheetham, Chem. Commun., 2012, 48, 7805-7807.

25 T. D. Bennett, S. Cao, J. C. Tan, D. A. Keen, E. G. Bithell, P. J. Beldon, T. Friscic and A. K. Cheetham, J. Am. Chem. Soc., 2011, 133, 14546-14549.

26 A. U. Ortiz, A. Boutin, A. H. Fuchs and F.-X. Coudert, J. Phys. Chem. Lett., 2013, 4, 1861-1865.

27 T. D. Bennett, D. A. Keen, J.-C. Tan, E. R. Barney, A. L. Goodwin and A. K. Cheetham, Angew. Chem., Int. Ed., 2011, 50, 3067-3071.

28 T. D. Bennett, P. Simoncic, S. A. Moggach, F. Gozzo, P. Macchi, D. A. Keen, J.-C. Tan and A. K. Cheetham, Chem. Commun., 2011, 47, 7983-7985. 
29 P. Zhao, G. I. Lampronti, G. O. Lloyd, M. T. Wharmby, S. Facq, A. K. Cheetham and S. A. T. Redfern, Chem. Mater., 2014, 26, 1767-1769.

30 T. D. Bennett and A. K. Cheetham, Acc. Chem. Res., 2014, 47, 1555-1562.

31 C. Orellana-Tavra, E. F. Baxter, T. Tian, T. D. Bennett, N. K. H. Slater, A. K. Cheetham and D. Fairen-Jimenez, Chem. Commun., 2015, 51, 13878.

32 B. B. Weksler, E. A. Subileau, N. Perrière, P. Charneau, K. Holloway, M. Leveque, H. Tricoire-Leignel, A. Nicotra, S. Bourdoulous, P. Turowski, D. K. Male, F. Roux, J. Greenwood, I. A. Romero and P. O. Couraud, FASEB J., 2005, 1872.

33 B. Weksler, I. Romero and P.-O. Couraud, Fluids Barriers CNS, 2013, 10, 16.

34 G. Frens, Nat. Phys. Sci., 1973, 241, 20-22.

35 B. Weksler, E. Subileau, N. Perriere, P. Charneau, K. Holloway, M. Leveque, H. Tricoire-Leignel, A. Nicotra, S. Bourdoulous, P. Turowski, D. Male, F. Roux, J. Greenwood, I. Romero and P. Couraud, FASEB J., 2005, 19, 1872-1874.

36 H. Ren, L. Zhang, J. An, T. Wang, L. Li, X. Si, L. He, X. Wu, C. Wang and Z. Su, Chem. Commun., 2014, 50, 1000-1002.

37 C.-Y. Sun, C. Qin, X.-L. Wang, G.-S. Yang, K.-Z. Shao, Y.-Q. Lan, Z.-M. Su, P. Huang, C.-G. Wang and E.-B. Wang, Dalton Trans., 2012, 41, 6906-6909.

38 L. He, T. Wang, J. An, X. Li, L. Zhang, L. Li, G. Li, X. Wu, Z. Su and C. Wang, CrystEngComm, 2014, 16, 3259-3263.

39 J. Zhuang, C.-H. Kuo, L.-Y. Chou, D.-Y. Liu, E. Weerapana and C.-K. Tsung, ACS Nano, 2014, 8, 2812-2819.

40 J. Cravillon, R. Nayuk, S. Springer, A. Feldhoff, K. Huber and M. Wiebcke, Chem. Mater., 2011, 23, 2130-2141.

41 T. Bennett, P. Saines, D. Keen, J.-C. Tan and A. Cheetham, Chem. - Eur. J., 2013, 19, 7049-7055.

42 D. Liu, B. Lin, W. Shao, Z. Zhu, T. Ji and C. Yang, ACS Appl. Mater. Interfaces, 2014, 6, 2131-2136.
43 Isoelectric Point Plugin, Journal, 2013.

44 D. A. Giljohann, D. S. Seferos and W. L. Daniel, Angew. Chem., Int. Ed., 2010, 49, 3280-3294.

45 L. Guang, L. Shaozhou, G. Zhen, K. F. Omar, G. H. Brad, Q. Xiaoying, W. Yi, W. Xin, H. Sanyang, L. Xiaogang, S. D. Joseph, Z. Hua, Z. Qichun, C. Xiaodong, M. Jan, L. Say Chye Joachim, D. W. Wei, Y. Yanhui, T. H. Joseph and H. Fengwei, Nat. Chem., 2012, 4, 310-316.

46 W. J. Rieter, K. M. Pott, K. M. L. Taylor and W. Lin, J. Am. Chem. Soc., 2008, 130, 11584-11585.

47 K. M. L. Taylor-Pashow, J. D. Rocca, Z. Xie, S. Tran and W. Lin, J. Am. Chem. Soc., 2009, 131, 14261-14263.

48 P. Horcajada, T. Chalati, C. Serre, B. Gillet, C. Sebrie, T. Baati, J. F. Eubank, D. Heurtaux, P. Clayette, C. Kreuz, J.-S. Chang, Y. K. Hwang, V. Marsaud, P.-N. Bories, L. Cynober, S. Gil, G. Ferey, P. Couvreur and R. Gref, Nat. Mater., 2010, 9, 172-178.

49 J. Della Rocca, D. Liu and W. Lin, Acc. Chem. Res., 2011, 44, 957-968.

50 P. Horcajada, C. Serre, M. Vallet-Regí, M. Sebban, F. Taulelle and G. Férey, Angew. Chem., Int. Ed., 2006, 45, 5974-5978.

51 D. K. Male, J. Cereb. Blood Flow Metab., 2009, 29, 1760-1763.

52 B. Poller, H. Gutmann, S. Krähenbühl, B. Weksler, I. Romero, P.-O. Couraud, G. Tuffin, J. Drewe and J. Huwyler, J. Neurochem., 2008, 107, 1358-1368.

53 A. Noack, S. Noack, A. Hoffmann, K. Maalouf, M. Buettner, P.-O. Couraud, I. A. Romero, B. Weksler, D. Alms, K. Römermann, H. Y. Naim and W. Löscher, PLoS One, 2014, 9, e88154.

54 R. Gromnicova, H. A. Davies, P. Sreekanthreddy, I. A. Romero, T. Lund, I. M. Roitt, J. B. Phillips and D. K. Male, PLoS One, 2013, 8, e81043.

55 J. V. Georgieva, D. Kalicharan, P.-O. Couraud, I. A. Romero, B. Weksler, D. Hoekstra and I. S. Zuhorn, Mol. Ther., 2011, 19, 318-325. 